\title{
Percent of Tumor Marker Positive Nuclei
}

National Cancer Institute

\section{Source}

National Cancer Institute. Percent of Tumor Marker Positive Nuclei. NCI Thesaurus.

Code C159485.

A quantitative measurement of the percent of nuclei that are positive for a nuclear tumor marker compared to the total number of nuclei in a sample. 